\title{
A Study on the Short-Term Mortality and Related Risk Factors of Fragile Hip Fracture
}

\author{
Pei-Wen Wang \\ The Second Affiliated Hospital of Fujian Medical University \\ Hua-Feng Zhuang \\ The Second Affiliated Hospital of Fujian Medical University \\ Yi-Zhong Li \\ The Second Affiliated Hospital of Fujian Medical University \\ Hao Xu \\ The Second Affiliated Hospital fo Fujian Medical University \\ Jin-Kuang Lin \\ The Second Affiliated Hospital of Fujian Medical University \\ Xue-Dong Yao ( $\square$ xdy123dr@163.com ) \\ The Second Affiliated Hospital of Fujian Medical University
}

\section{Research article}

Keywords: Hip, Fragile fractures, Mortality, Risk factors, Anti-osteoporosis treatment

Posted Date: December 18th, 2020

DOI: https://doi.org/10.21203/rs.3.rs-129838/v1

License: (c) (1) This work is licensed under a Creative Commons Attribution 4.0 International License. Read Full License 


\section{Abstract}

Background

This study aimed to observe the mortality of patients with fragile hip fractures and assess the death-associated risk factors.

Methods

Six hundred and ninety patients with osteoporotic hip fractures(aged 50-103-years-old) that were treated from January 2010 to December 2015 were enrolled in this study and followed-up and the clinical data were retrospectively examined. Three months, one year, and the total mortality during the follow-up time were measured. Mortality-related risk factors were assessed including age, gender, surgery, the duration from injury to operation, pulmonary infection, and the number and type of complications.

Results

The 286 patients were followed up between 6 months and 42 months, with an average of $21.42 \pm 9.88$ months. The three-month mortality was $7.69 \%$, the number of patients who were followed up over one year was 231 , the one-year mortality was $16.02 \%$, and the total mortality of the follow-up time was $17.48 \%$. The higher mortality was related to age over 75 years, associated cardio-respiratory diseases, male gender, non-operative treatment, surgery delayed over 5 days. Binary Logistic regression analysis showed that the independent risk factors affecting mortality included age $(0 R=5.385$, $P=0.003)$, surgery $(\mathrm{OR}=21.217, \mathrm{P}=0.000)$, the number of complications $(\mathrm{OR}=9.038, \mathrm{P}=0.000)$, and pre-injury cardiovascular disease $(\mathrm{OR}=3.201, \mathrm{P}=0.041)$.

\section{Conclusion}

The early mortality of fragile hip fractures was high and was also related to many risk factors. Age, surgery, the number of complications, and pre-injury cardiovascular disease were the independent risk factors affecting the mortality of patients with fragile hip fractures. Effective treatment without complications and early surgery can lower early mortality in patients with fragile hip fractures.

\section{Background}

A fragile fracture is osteoporosis fracture, a type of fracture caused by low-energy trauma without obvious trauma and it is the most serious complication of osteoporosis. More than half of women and approximately $1 / 3$ of the men are likely to have fragile fractures in their lives [1]. The prevalence of fragile hip fractures (including femoral neck fracture and intertrochanteric fracture) is increasing. In 2000, there were approximately 1.5 million cases of fragile hip fractures in patients over 60-years-old worldwide [2] and it is estimated that the incidence rate will reach 6.26 million by 2050 , among which Asians will account for over $50 \%$ of the cases [3]. Approximately 1 million people suffer from hip fractures every year in China, most of them are elderly patients, and the incidence rate has increased visibly. From 2002-2006, the annual incidence of hip fractures increased by approximately 10\% [4]. Fragile hip fracture is a worldwide public health concern, which causes more burden to the medical system. Since elderly patients often have other diseases before the injury, the risk of operation for hip fracture and the postoperative disability rate are high while the mortality rate after a fracture is also generally at a higher level [5-7]. Foreign research has reported that within one year after a hip fracture, $30 \%$ of patients died from various complications and $50 \%$ of them were disabled $[8,9]$. Compared with that of the healthy elderly population, the 1 -year mortality after hip fracture increases by $27.2 \%$ in male patients and by $17.1 \%$ in female patients [10]. The risk of death after fragile hip fractures in the elderly population can last for 10 years [11]. Previous Chinese literature has also reported that $12-20 \%$ of patients with a fragile hip fracture may die within 1 year, $50 \%$ of them need other people's care for daily living activities, and none of them recovered to the level before the fracture [12].

At present, many factors influence the mortality of osteoporotic hip fracture reported in the literature, such as age, gender, treatment method, operation time, the American Society of Anesthesiologists (ASA) grade, number and type of combined medical diseases, post-injury complications, anti-

osteoporosis treatment, and walking ability before the fracture $[13,14]$. Whether these factors affect the death of patients with fragile hip fracture remains debated. Some scholars have found that men have a major risk factor for mortality from fragile hip fractures $[15,16]$. However, other studies have shown that through multivariate analysis, there was no significant difference in the mortality rate of fragile hip fracture between men and women [13]. Moran et al. [17] advised that the delayed operation for more than 4 days after the fragile hip fracture would significantly increase mortality, while Vidal et al. [18] suggested that the time from injury to operation was not associated with high risk of mortality of patients with fragile hip fractures.

Since fragile hip fractures are a common cause of death in the elderly population, it is necessary to recognize the associated factors that affect the mortality of patients with fragile hip fractures. Therefore, this study retrospectively examined the inpatient medical records and follow-up data of 690 fragile hip fracture patients over 50-years-old who were admitted to our hospital from January 2010 to December 2015 and were followed up to achieve the following purposes: (1) Understand the mortality of patients with fragile hip fractures in three months, one year, and during the follow-up period; (2) Analyze the risk factors for short-term mortality in fragile hip fracture patients; (3) According to the results of the examination, prevent and reduce these risk factors by employing the corresponding treatment measures to decrease mortality after injury.

\section{Materials And Methods}

\subsection{Inclusion and exclusion criteria}


Inclusion criteria: (1) Patients aged $\geq 50$-years-old; (2) Patients with a fragile hip fracture and presumably most of them had a trivial fall before the fracture.

Exclusion criteria: (1) Patients aged < 50-years-old; (2) Patients with severe violent trauma, such as traffic accident, falling from a high place, and high energy impact injury; (3) Patients with a pathological fracture of the hip caused by primary or metastatic tumors.

\subsection{General information}

From January 2010 to December 2015, 13089 fracture patients were admitted to our hospital. A total of 1211 patients with a fragile hip fracture aged over 50-years-old, among which 690 patients were followed up (56.98\%), the age ranged within 50-103-years-old and the average age was $77.19 \pm$ 10.38 years old. Of the 690 patients, 234 were male, the average age was $75.27 \pm 11.46$ years old and 456 patients were female, the average age was $79.52 \pm 9.87$ years old. Three hundred and thirty-five patients had femoral neck fracture and 355 patients had intertrochanteric fracture; 611 patients were treated by operation, including 283 patients by artificial joint replacement, 328 patients by internal fixation, and 79 patients by non-operative treatments. This study was conducted in accordance with the declaration of Helsinki and approved by the Ethics Committee of the Second Affiliated Hospital of Fujian Medical University. Informed consent was obtained from all individual participants included in the study. The general conditions of these 690 patients are shown in Table 1.

Table 1

The general conditions of the 690 patients

\begin{tabular}{|c|c|c|c|c|}
\hline Item & Femoral neck fracture $(n=335)$ & Intertrochanteric fracture $(n=355)$ & Total (n) & Follow-up over 1 year $(n)$ \\
\hline \multicolumn{5}{|l|}{ Gender } \\
\hline Male & 102 & 132 & 234 & 219 \\
\hline Female & 233 & 223 & 456 & 416 \\
\hline \multicolumn{5}{|l|}{ Treatment measures } \\
\hline Operative treatment & 304 & 307 & 611 & 560 \\
\hline Nonoperative treatment & 34 & 45 & 79 & 75 \\
\hline \multicolumn{5}{|l|}{ Combined medical diseases } \\
\hline One kind & 99 & 114 & 213 & 201 \\
\hline Two kinds & 86 & 83 & 169 & 152 \\
\hline Three or more kinds & 32 & 27 & 59 & 49 \\
\hline Cardiovascular disease & 186 & 178 & 364 & 329 \\
\hline Diabetes & 42 & 50 & 92 & 86 \\
\hline Cerebrovascular disease & 51 & 47 & 98 & 87 \\
\hline Respiratory disease & 12 & 25 & 37 & 31 \\
\hline Other medical diseases & 21 & 22 & 43 & 37 \\
\hline Lung infection & 54 & 61 & 115 & 107 \\
\hline Anti-osteoporosis & 243 & 233 & 478 & 448 \\
\hline Non-anti-osteoporosis treatment & 92 & 122 & 212 & 187 \\
\hline \multicolumn{5}{|l|}{ Age } \\
\hline $50-59$ (years) & 23 & 17 & 40 & 35 \\
\hline $60-69$ (years) & 58 & 41 & 99 & 93 \\
\hline 70-79(years) & 106 & 90 & 196 & 180 \\
\hline 80-89(years) & 121 & 165 & 286 & 262 \\
\hline$\geq 90$ (years) & 27 & 42 & 69 & 65 \\
\hline
\end{tabular}

There were 444 patients with cardiovascular disease, diabetes, cerebrovascular disease, chronic respiratory disease, and other medical diseases, which were diagnosed according to the following criteria.

Cardiovascular disease: (1) Hypertension, blood pressure $\geq 140 / 90$ mmHg occurred at least 3 times on different days; (2) Coronary heart disease, a previous diagnosis and treatment history by cardiologists, electrocardiogram (ECG) showed ST-segment depression by $\geq 0.1 \mathrm{mV}$; (3) Arrhythmia, indicated by ECG; (4) Heart failure, New York Heart Association (NYHA) cardiac function grades II-IV; (5) Old myocardial infarction, previous history of myocardial infarction, ECG showed pathological Q wave. 
Diabetes mellitus: type 1 and type 2 diabetes, fasting blood glucose of $\geq 7 \mathrm{mmol} / \mathrm{L}, 2$-hours postprandial or random blood glucose of $\geq 11.1 \mathrm{mmol} / \mathrm{L}$.

Cerebrovascular disease: (1) Cerebral infarction, cerebral CT or MRI showed cerebral infarction; (2) Sequelae of cerebrovascular accident, previous history of cerebral infarction or cerebral hemorrhagic disease and limb paralysis; (3) Parkinson's disease, previous diagnosis and treatment history by a neurologist, static tremor; (4) Brain atrophy, indicated by craniocerebral CT or MRI.

Chronic respiratory diseases: (1) Chronic bronchitis, chronic cough, expectoration for $\geq 3$ months, lasting more than 2 years; (2) Chronic obstructive pulmonary disease, chronic cough, expectoration, dyspnea, and previous diagnosis by pulmonary function examination; (3) Pulmonary tuberculosis, previous diagnosis and treatment history by respiratory specialists or indicated by a chest X-ray and CT; (3) Atelectasis, indicated by a chest X-ray or CT.

Other medical diseases: (1) Hypoalbuminemia, serum albumin of < $35 \mathrm{~g} / \mathrm{L}$; (2) Liver cirrhosis, indicated by B ultrasound or CT, and abnormal liver function occurred; (3) Renal insufficiency, creatinine clearance rate of $\leq 90 \mathrm{~mL} / \mathrm{min}$; (4) Rheumatoid arthritis, a history of diagnosis and treatment by a former rheumatologist, positive rheumatoid factor (RF).

Anti-osteoporosis treatment: (1) Active vitamins, calcium agent + active vitamin D; (2) Calcitonin + calcium agent + vitamin D; (3) Bisphosphonate + calcium agent + vitamin D.

\subsection{Methods}

The patients' in-hospital medical records with fragile hip fractures were retrospectively examined, the patients' survival was followed-up, and in case of death, the time from injury to death was recorded, and the 3-month, 1-year,and total mortality during the whole follow-up period were calculated. The risk factors related to mortality were also examined, including age, gender, surgical treatment, the time from injury to operation, pulmonary infection during hospitalization, the number and type of combined medical diseases, anti-osteoporosis treatment, etc.

\subsection{Statistical methods}

Data were analyzed using statistical software SPSS21.0 (USA). A Chi-square test or Chi-square test after correction was used for the univariate analysis of the count data (percentage) between the two groups and the factors with statistical significance confirmed by the univariate analysis were examined by binary logistic regression analysis. $\mathrm{P}<0.05$ was considered statistically significant.

\section{Results}

The follow-up duration for the 690 patients ranged within 7-52 months and the average duration was $28.53 \pm 9.75$ months. Within 3 months of the follow-up, 46 patients died and the mortality rate was $7.69 \%$ (46/690). Among the 635 patients who were followed up for more than 1 year, 99 patients died within 1 year and the mortality rate was $15.60 \%$ (99/635). A total of 166 deaths occurred during the follow-up period and the total mortality was $24.06 \%(166 / 690)$.

\subsection{The univariate analysis of mortality}

\subsubsection{The impact of age on mortality}

The patients in this study were divided into 2 groups according to their ages: the $\leq 75$-year-old group and the > 75-year-old group. The 3-month, 1-year, and total mortality during the follow-up of the patients were higher in the $>75$-year-old group than those in the $\leq 75$-year-old group. The differences in 1 year mortality and the total mortality during the follow-up period between the 2 groups were statistically significant $(P<0.05, T a b l e ~ 2)$. 
Table 2

Results of single factor analysis of single factor effect on mortality

\begin{tabular}{|c|c|c|c|c|c|c|c|c|c|c|c|c|c|c|}
\hline \multirow{2}{*}{$\begin{array}{l}\text { Related } \\
\text { factors }\end{array}$} & \multirow[t]{2}{*}{ Total } & \multirow{2}{*}{$\begin{array}{l}\text { Follow- } \\
\text { up } \\
\text { over } \\
1 \text { year } \\
\text { (n) }\end{array}$} & \multicolumn{4}{|c|}{ 3-month mortality } & \multicolumn{4}{|c|}{ 1-year mortality } & \multicolumn{4}{|c|}{ Total mortality during follow-up } \\
\hline & & & $\mathrm{n}$ & $\begin{array}{l}\text { Mortality } \\
\text { (\%) }\end{array}$ & $x^{2}$ & $\begin{array}{l}\mathrm{P} \\
\text { value }\end{array}$ & $\mathbf{n}$ & $\begin{array}{l}\text { Mortality } \\
\text { (\%) }\end{array}$ & $x^{2}$ & $\begin{array}{l}P \\
\text { value }\end{array}$ & $\mathbf{n}$ & $\begin{array}{l}\text { Mortality } \\
\text { (\%) }\end{array}$ & $\chi^{2}$ & $\begin{array}{l}P \\
\text { value }\end{array}$ \\
\hline Age & & & & & 1.705 & 0.192 & & & 21.243 & 0.000 & & & 37.705 & 0.000 \\
\hline$\leq 75$ & 221 & 203 & 6 & 2.71 & & & 12 & 5.91 & & & 21 & 9.50 & & \\
\hline$\otimes 75$ & 469 & 432 & 40 & 8.53 & & & 87 & 20.14 & & & 145 & 30.92 & & \\
\hline Gender & & & & & 3.030 & 0.082 & & & 4.155 & 0.042 & & & 5.713 & 0.017 \\
\hline Male & 234 & 219 & 21 & 8.97 & & & 43 & 19.63 & & & 69 & 29.49 & & \\
\hline Female & 456 & 416 & 25 & 5.48 & & & 56 & 13.46 & & & 97 & 21.27 & & \\
\hline $\begin{array}{l}\text { Treatment } \\
\text { measures }\end{array}$ & & & & & 72.246 & 0.000 & & & 132.467 & 0.000 & & & 102.53 & 0.000 \\
\hline $\begin{array}{l}\text { Surgical } \\
\text { treatment }\end{array}$ & 611 & 559 & 23 & 3.76 & & & 53 & 9.48 & & & 112 & 18.33 & & \\
\hline $\begin{array}{l}\text { Non- } \\
\text { surgical } \\
\text { treatment }\end{array}$ & 79 & 76 & 23 & 29.11 & & & 46 & 60.52 & & & 54 & 71.05 & & \\
\hline \multicolumn{2}{|c|}{$\begin{array}{l}\text { Time from the } \\
\text { injury to the } \\
\text { operation }\end{array}$} & & & & 3.880 & 0.049 & & & 7.013 & 0.008 & & & 13.974 & 0.000 \\
\hline$\leq 5$ days & 225 & 198 & 4 & 1.78 & & & 10 & 5.05 & & & 24 & 10.67 & & \\
\hline$>5$ days & 386 & 361 & 19 & 4.92 & & & 43 & 11.91 & & & 88 & 22.80 & & \\
\hline $\begin{array}{l}\text { Lung } \\
\text { infection }\end{array}$ & & & & & 6.727 & 0.010 & & & 9.093 & 0.003 & & & 4.975 & 0.026 \\
\hline Yes & 115 & 107 & 14 & 12.17 & & & 27 & 25.23 & & & 37 & 32.17 & & \\
\hline NO & 575 & 528 & 32 & 5.57 & & & 72 & 13.64 & & & 109 & 22.43 & & \\
\hline \multicolumn{2}{|c|}{$\begin{array}{l}\text { Number of } \\
\text { combined medical } \\
\text { diseases }\end{array}$} & & & & 10.111 & 0.001 & & & 15.358 & 0.000 & & & 16.524 & 0.000 \\
\hline$<2$ kinds & 462 & 434 & 21 & 4.55 & & & 51 & 11.75 & & & 97 & 21.00 & & \\
\hline$\geq 2$ kinds & 228 & 201 & 25 & 10.96 & & & 48 & 23.88 & & & 69 & 30.26 & & \\
\hline \multicolumn{2}{|c|}{$\begin{array}{l}\text { Combined } \\
\text { vascular disease }\end{array}$} & & & & 4.237 & 0.040 & & & 6.569 & 0.010 & & & 3.462 & 0.062 \\
\hline Yes & 364 & 329 & 31 & 8.52 & & & 63 & 19.15 & & & 98 & 26.92 & & \\
\hline No & 326 & 306 & 15 & 4.60 & & & 36 & 11.76 & & & 68 & 20.86 & & \\
\hline $\begin{array}{l}\text { Combined } \\
\text { diabetes }\end{array}$ & & & & & 0.402 & 0.402 & & & 3.196 & 0.074 & & & 2.363 & 0.124 \\
\hline Yes & 92 & 86 & 8 & 8.70 & & & 19 & 22.09 & & & 28 & 30.43 & & \\
\hline No & 598 & 549 & 38 & 6.35 & & & 80 & 14.57 & & & 138 & 23.08 & & \\
\hline \multicolumn{2}{|c|}{$\begin{array}{l}\text { Combined } \\
\text { cerebrovascular } \\
\text { disease }\end{array}$} & & & & 0.411 & 0.521 & & & 0.209 & 0.648 & & & 0.132 & 0.717 \\
\hline Yes & 98 & 87 & 8 & 8.16 & & & 15 & 17.24 & & & 25 & 25.51 & & \\
\hline No & 592 & 548 & 38 & 6.42 & & & 84 & 15.33 & & & 141 & 23.82 & & \\
\hline $\begin{array}{l}\text { Combined } \\
\text { respiratory } \\
\text { disease }\end{array}$ & & & & & 2.946 & 0.086 & & & 4.475 & 0.034 & & & 2.626 & 0.105 \\
\hline Yes & 37 & 31 & 5 & 13.51 & & & 9 & 29.03 & & & 13 & 35.14 & & \\
\hline No & 653 & 604 & 41 & 6.28 & & & 90 & 14.90 & & & 153 & 23.43 & & \\
\hline \multicolumn{2}{|c|}{ Anti-osteoporosis } & & & & 31.131 & 0.000 & & & 22.685 & 0.000 & & & 9.537 & 0.002 \\
\hline
\end{tabular}




\begin{tabular}{|c|c|c|c|c|c|c|c|c|c|c|c|c|c|c|}
\hline \multirow{2}{*}{$\begin{array}{l}\text { Related } \\
\text { factors }\end{array}$} & \multirow[t]{2}{*}{ Total } & \multirow{2}{*}{$\begin{array}{l}\text { Follow- } \\
\text { up } \\
\text { over } \\
1 \text { year } \\
\text { (n) }\end{array}$} & \multicolumn{3}{|c|}{ 3-month mortality } & \multicolumn{5}{|c|}{ 1-year mortality } & \multicolumn{4}{|c|}{ Total mortality during follow-up } \\
\hline & & & $\mathrm{n}$ & $\begin{array}{l}\text { Mortality } \\
(\%)\end{array}$ & $x^{2}$ & $\begin{array}{l}P \\
\text { value }\end{array}$ & $\mathrm{n}$ & $\begin{array}{l}\text { Mortality } \\
(\%)\end{array}$ & $x^{2}$ & $\begin{array}{l}P \\
\text { value }\end{array}$ & $\mathrm{n}$ & $\begin{array}{l}\text { Mortality } \\
(\%)\end{array}$ & $x^{2}$ & $\begin{array}{l}P \\
\text { value }\end{array}$ \\
\hline Yes & 478 & 448 & 15 & 3.14 & & & 50 & 11.16 & & & 99 & 20.71 & & \\
\hline No & 212 & 187 & 31 & 14.62 & & & 49 & 26.20 & & & 67 & 31.60 & & \\
\hline
\end{tabular}

\subsubsection{The impact of gender on mortality}

The 3-month, 1-year, and total mortalities during the follow-up were higher in the male patients than in the female patients. The differences in 1-year mortality and the total mortality during the follow-up period between the 2 groups were statistically significant $(P<0.05$, Table 2$)$.

\subsubsection{The impact of surgery on mortality}

The 3-month, 1-year,and total mortality during the follow-up period were significantly lower in the operation group than in the non-operation group, the differences between the 2 groups were statistically significant $(P<0.05$, Table 2$)$.

\subsubsection{The impact of the interval from injury to surgery on mortality}

The 3-month, 1-year, and total mortality during the follow-up period were significantly lower in the patients that underwent the operation in $\leq 5$ days than the patients that underwent the operation within $>5$ days, the differences between the 2 groups were statistically significant $(P<0.05$, Table 2$)$.

\subsubsection{The impact of pulmonary infection on mortality}

The 3-month, 1-year, and total mortality during the follow-up period were significantly higher in the patients with in-hospital pulmonary infection than in patients without pulmonary infection, the differences between the 2 groups were statistically significant $(P<0.05, T a b l e ~ 2)$.

\subsubsection{The impact of the number of combined medical diseases on mortality}

The 3-month, 1-year,and total mortality during the follow-up period were significantly lower in patients with $>2$ kinds of chronic diseases than those with $\geq 2$ kinds of chronic diseases, the differences between the 2 groups were statistically significant $(P<0.05, T a b l e 2)$.

\subsubsection{The impact of the types of combined medical diseases on mortality}

The 3-month, 1-year,and total mortality during the follow-up period were higher in patients with cardiovascular diseases than in patients without cardiovascular diseases, the differences in the 3-month and 1-year mortalities between the 2groups were statistically significant ( $P<0.05$, Table 2$)$. The 3month, 1-year, and total mortality during the follow-up period were higher in patients with respiratory diseases than in patients without respiratory diseases, but only the difference in 1-year mortality between the 2groups was statistically significant $(P=0.034$, Table 2). The differences in 3-month, 1year,and total mortality during the follow-up period between patients with or without diabetes and between patients with or without cerebrovascular diseases were not statistically significant $(P>0.05$, Table 2$)$.

\subsubsection{The impact of anti-osteoporosis treatment on mortality}

The 3-month, 1-year, and total mortality during the follow-up period were significantly lower in patients receiving anti-osteoporosis treatment than in patients not receiving anti-osteoporosis treatment, the differences between the 2 groups were statistically significant $(P<0.05, T a b l e ~ 2)$.

\subsection{The multivariate analysis of mortality}

Using the factors with statistical significance in the univariate analysis as independent variables and the total mortality of patients in the follow-up period as dependent variables, the multivariate logistic regression analysis was conducted. The results revealed that advanced age $>75$-years-old $(\mathrm{OR}=5.653, \mathrm{P}$ $=0.003)$, male $(O R=1.998, P=0.001)$, non-surgical treatment $(O R=9.909, P=0.000)$, the number of combined medical diseases $\geq 2(O R=1.522, P=$ 0.042), and non-anti-osteoporosis treatment $(O R=1.796, P=0.002)$ were independent risk factors for the short-term mortality in patients with fragile hip fractures (Table 3).

Table 3

Multivariate analysis results of recent death risk of fragile hip fracture

\begin{tabular}{|lllllll|}
\hline Influence factor & Bvalue & $\chi 2$ value & P value & OR value & \multicolumn{2}{l|}{$95 \% \mathrm{Cl}$} \\
\cline { 5 - 8 } & & & & & Lower limit & Upper limit \\
\hline Age & 1.732 & 38.283 & 0.000 & 5.653 & 3.266 & 9.784 \\
\hline Gender & 0.692 & 10.844 & 0.001 & 1.998 & 1.323 & 3.017 \\
\hline Surgical treatment or not & 2.208 & 62.531 & 0.000 & 9.909 & 5.263 & 15.726 \\
\hline Number of combined medical diseases & 0.420 & 4.154 & 0.042 & 1.522 & 1.016 & 2.278 \\
\hline Anti-osteoporosis treatment & 0.586 & 9.975 & 0.002 & 1.796 & 1.249 & 2.584 \\
\hline
\end{tabular}




\section{Discussion}

The data in this study showed that in a population with an age over 50-years-old, with the increase in age, the incidence of hip fractures increased and 70 89-years-old is the high incidence age of fragile hip fractures because of the decrease in activity and the number of cases reduced in the elderly aged over 90 -years-old. The mortality of patients with fragile hip fractures increased with age. Previous studies also revealed that advanced age increased the $1-$ year mortality of hip fracture patients $[10,19]$. Statistical data in this study revealed that the 3-month, 1-year,and total mortality during the follow-up period of patients with an age $>75$-years-old were higher than those in patients with an age $\leq 75$-years-old. Among the patients over 75-years-old, the 1year mortality was $20.14 \%$, and the total mortality during the follow-up period was as high as $30.92 \%$. The difference was statistically significant compared with the patients with an age $\leq 75$-years-old. The multivariate analysis also confirmed that age was an independent risk factor for short-term mortality in patients with fragile hip fractures.

Women are also more likely to have hip fractures than men; in the present study, the ratio of male to female was 1:1.95. Previous studies have revealed that the male gender was a major risk factor for mortality from fragile hip fractures $[15,16]$. After the hip fracture occurs, the life expectancy of the elderly will be greatly reduced and the physical life of females was decreased by 4 years when compared with the life expectancy, while that of males was decreased by 5 years [20]. Kannegaard et al. [10] reported that compared with females, the average age of onset of fragile hip fractures was 4 years younger in males and mortality was significantly higher. However, some reports revealed that mortality in patients with fragile hip fractures was not related to gender $[13,21]$. This study revealed that when compared with females, the average age of onset of fragile hip fractures was 4.24 years younger in males, the 3-month, 1-year,and total mortality during the follow-up period were higher in males than in females, and the differences in the 1-year and total mortality during the follow-up period between males and females were statistically significant. This result suggests that although the incidence and age of onset of fragile hip fractures were lower in males, the mortality was higher in males than in females, and this was established by the multivariate analysis, showing that the male gender was an independent risk factor for short-term mortality in patients with fragile hip fractures. This is consistent with the findings of previous studies conducted by many scholars $[15,16]$.

The purpose of fragile hip fracture treatment is to allow patients to continue with painless activities and get out of bed to reduce the complications caused by long-term bed rest and reduce the fatality and disability rate. Currently, the treatment of fragile hip fractures is mainly surgery and conservative treatment. In general, tibial tubercle bone traction or lower extremity skin traction are used for conservative treatment. However, this requires patients needing long-term bed rest and possibly induces pulmonary infection, bedsores, urinary system infection, lower limb venous thrombosis, and other complications while significantly reducing the patients' quality of life and the fatality rate is high. Therefore, surgery remains the main treatment for hip fracture patients with fairly stable general conditions and patients that are tolerable to surgery. The main surgical methods are internal fixation and artificial joint replacement [22]. In the present study, the 3-month, 1-year,and total mortality during the follow-up period was $3.76 \%, 9.48 \%$, and $18.33 \%$, respectively in the operation group and were far lower than in the non-operation group $(29.11 \%, 60.52 \%$, and $71.05 \%$, respectively), the differences were statistically significant. It was also confirmed by multivariate analysis that the non-operative treatment was an independent risk factor for short-term mortality in patients with fragile hip fractures. This fully demonstrates that the operation treatment of fragile hip fracture has a significant positive effect.

The association between delayed surgery and mortality after fragile hip fractures in the elderly population remains a major issue [23, 24]. Some scholars consider that the earlier the operation and even the emergency operation is performed, the better the effect is. Shiga et al. [25] reported that an operation completed at more than 48 hours after the fragile hip fracture will increase the 1-month and 1-year mortality in patients. Some other scholars believe that the operation should not be performedina rush and that there should be enough time to treat the internal diseases of the elderly patients before surgery. Preoperative preparation and evaluation should also be enhanced to reduce the risk of the operation and its success rate. Vidal et al. [18] showed in their studies that the time from injury to operation was not associated with the in-hospital and 1-year mortality after surgery while Kim et al. [26] showed that a delayed operation would not affect the postoperative complications of hip fractures. In the present study, all the patients had slight trauma and no obvious trauma, some of the patients did not even realize that they had afracture but were admitted to the hospital after the pain was not improved for 1-2 days. After admission, due to the advanced age of the patients, the hospital had no preoperative green channel for hip fractures, so preoperative preparations required 3-4 days. Therefore, in the present study, an interval from injury to the operation of 5 days was set as the grouping boundary. The researchers observed that although the 3-month, 1-year,and total mortality during the follow-up period were lower in patients with the interval from injury to the operation of $\leq 5$ days than in patients with the interval from injury to the operation of $>5$ days, the differences were statistically significant. However, it was established by multivariate analysis that the interval from injury to operation was not an independent risk factor for short-term mortality in patients with fragile hip fractures. Therefore, the researchers considered that the selection of operation time for elderly patients with hip fractures should follow the principle of individualization and should be lengthily measured according to the patient's physical condition. Patients that can tolerate the operation should be operated as early as possible to reduce the difficulties of bed rest while the patients with poor physical conditions should have enough time for the preoperative planning.

Elderly patients with hip fractures regularly have multiple internal diseases and poor organ compensatory function. Surgery will worsen the existing combined medical diseases and even lead to death. A previous study described that the mortality after hip fractures was associated with chronic diseases such as hypertension, diabetes, ischemic heart disease, and stroke [27]. Moran et al. [17] showed that the risk of death 30 days after surgery in patients with fragile hip fractures combined with internal diseases was 2.5 times higher than in patients without internal diseases. The findings of the present study are similar; of these 690 patients, 441 patients had various internal chronic diseases, up to $63.91 \%$, of patients had 2 or more chronic diseases, the 3-month mortality was $10.96 \%$, the 1 -year mortality was $23.88 \%$, and the total mortality was $30.26 \%$.All the results were higher than the mortality of patients with $<2$ medical chronic diseases. In patients who had cardiovascular diseases or chronic respiratory system diseases before the operation, the mortality was also statistically and significantly increased. The multivariate analysis revealed that the number of internal diseases before

Page $7 / 10$ 
the injury was an independent risk factor for short-term mortality in patients with fragile hip fractures. The treatment of medical diseases before surgery is directly associated with the success of the operation and the prognosis in patients. Therefore, after admission, patients should actively collaborate with the physician to treat their combined diseases and physicians should measure patients' tolerance to surgery to select a tolerable operation to reduce the mortality in elderly patients with fragile hip fractures.

The incidence of difficulties after fragile hip fractures is high and the main complications include pulmonary infection, heart event, deep vein thrombosis of the lower extremity, delirium, and cerebrovascular accidents. Fang et al. [28] consider that pulmonary infection and respiratory failure are frequently the main causes of death in these patients. In the present study, pulmonary infection occurred in 115 patients during hospitalization, 37 of them died during hospitalization and the follow-up period and the 3-month, 1-year,and total mortality during the follow-up period were significantly higher in patients with in-hospital pulmonary infection than in patients without in-hospital pulmonary infection; the differences were statistically significant. These findings indicate that in-hospital pulmonary infection is a significant risk factor for short-term mortality in patients with fragile hip fractures. However, given the interaction between various factors, the multivariate analysis showed that in-hospital pulmonary infection was not an independent risk factor for shortterm mortality in patients with fragile hip fractures.

Anti-osteoporosis treatment has been confirmed to effectively reduce the risk of succeeding fractures and improves the functional outcome of hip fracture patients [29]. This leads to a hypothesis, that is, osteoporosis drug treatment can reduce the risk of death in patients with fragile hip fractures. Zoledronic acid has also been confirmed to significantly increase bone mineral density in the hip and lumbar spine, reduce the risk of new clinical fractures by $35 \%$ and reduce the risk of death in patients with recurrent fractures within 3 years by $28 \%$ [ 30 ]. In the present study, it was also confirmed that anti-osteoporosis treatment (including Bisphosphonates and non-Bisphosphonates) was significantly related to a reduction in short-term mortality in fragile hip fractures. Furthermore, it was established by the multivariate analysis that the absence of anti-osteoporosis treatment was an independent risk factor for short-term mortality in patients with fragile hip fractures.

This retrospective study had several limitations. Firstly, only $56.98 \%$ of the hip fracture patients were followed-up successfully and this was a retrospective and not a randomized study.

Secondly, the present study did not include all the aspects that may affect the prognosis of patients with fragile hip fractures, such as the patients' activity function before the injury, ASA score before surgery, and the surgeons' surgical skills. Thirdly, whether the basis for grouping the factors involved in this study was reasonable, for example, 75-years-old was set as the boundary of age and 5 days was set as the boundary of the interval from injury to operation, needs to be studied further.

\section{Conclusion}

In summary, the short-term mortality of elderly patients with fragile hip fractures is high. Death after the injury is the outcome of an interaction of many factors, but different influences have different impacts on mortality. In the present study, age, whether or not surgical treatment was performed, the number of medical diseases, and whether or not anti-osteoporosis treatment was performed had the greatest impact on mortality. These factors were independent risk factors for short-term mortality in patients with fragile hip fractures. Therefore, the short-term mortality of patients in the future can be reduced by vigorously addressing the internal diseases and operating on the patients as soon as possible.

\section{Declarations}

\section{Ethics approval and consent to participate}

All procedures performed in studies involving human participants were in accordance

with the ethical standards of The Second Affiliated Hospital of Fujian Medical University research committee and with the 1964 Helsinki declaration and its later amendments or comparable ethical standards. All participants gave their informed consent in writing prior to inclusion in the study.

\section{Consent for publication}

Not applicable

\section{Availability of data and materials}

The datasets generated and/or analysed during the current study are not publicly available due to the lack of an online platform but are available from the corresponding author on reasonable request.

\section{Competing interests}

The authors declare that they have no competing interests.

\section{Funding}

This work was supported by Innovative Talents Project of Science and Technology Plan of Quanzhou (No. 2018C046R). 


\section{Authors' contributions}

PWW and XDY been involved in drafting the manuscript and revising it critically for important intellectual content and conception and design; HFZ, YNZ and HX made substantial contributions to acquisition and interpretation of data; JKL analyzed the data; All authors given final approval of the version to be published.

\section{References}

1. Wells GA, Cranney A, Peterson J, et al. Alendronate for the primary and secondary prevention of osteoporotic fractures in postmenopausal women. Cochrane Database Syst Rev. 2008;23(1): CD001155.

2. Johnell O, Kanis JA. An estimate of the worldwide prevalence and disability associated with osteoporotic fractures. Osteoporos Int. 2006;17(12):1726-1733.

3. Cooper C, Cole ZA, Holroyd CR, et al. Secular trends in the incidence of hip and other osteoporotic fractures. Osteoporos Int. 2011;22(5):1277-

4. Xia WB, He SL, Xu L, et al. Rapidly increasing rates of hip fracture in Beijing, China. Bone Miner Res. 2012;27(1): 125-129.

5. Leung KS, Yuen WF, Ngai WK, Lam CY, Lau TW, Lee KB, Siu KM, Tang N, Wong SH, Cheung WH. How well are we managing fragility hip fractures? A narrative report on the review with the attempt to setup a Fragility Fracture Registry in Hong Kong. Hong Kong Med J. 2017;23:264-271.

6. Omsland TK, Emaus N, Tell GS, Magnus JH, Ahmed LA, Holvik K, Center J, Forsmo S, Gjesdal CG, Schei B, et al. Mortality following the first hip fracture in Norwegian women and men (1999-2008). A NOREPOS study. Bone. 2014;63:81-86.

7. Lin JK, Li YZ, Yu HM, Yao XD, Zhuang HF. Rivaroxaban for the prevention of lower extremity deep vein thrombosis after hip fracture in the elderly. Chinese Journal of Orthopaedic Trauma 2011;13(9):885-887.

8. Karagiannis A, Papakitsou E, Dretakis K, et a1. Mortality rates of patients with a hip fracture in a southwestern district of Greece: ten-year follow-up with reference to the type of fracture. Calcif Tissue Int. 2006;78:72-77.

9. Leung F, Blauth M, Bavonratanavech S. Surgery for fragility hip fracture-streamlining the process. Osteoporosis Int. 2010;21:519-521.

10. Kannegaard PN, Van Der Mark S, Eiken P, Abrahamsen B. Excess mortality in men compared with women following a hip fracture. National analysis of comedications, comorbidity and survival. Age Ageing. 2010;39(2):203-209.

11. Dana Bliuc, Nguyen D, Vivienne VE, Nguyen TV, Eisman JA, Center JR.. Mortality Risk Associated With Low-Trauma Osteoporotic Fracture and Subsequent Fracture in Men and Women. 2009;301(5):513-521.

12. Editorial Board of Osteoporosis Prevention and Treatment (China White Paper). China Health Promotion Foundation.White paper on osteoporosis.Chin J Health Manage. 2009;3(3):148-154.

13. Karademir G, Bilgin Y, Ersen A, Polat G, Buget MI, Demirel M, Balci HI. Hip fractures in patients older than 75 years old: retrospective analysis for prognostic factors. Int J Surg. 2015;24:101-104.

14. losifidis M, lliopoulos E, Panagiotou A, Apostolidis K, Traios S, Giantsis G.Walking ability before and after a hip fracture in elderly predict greater longterm survivorship. J Orthop Sci. 2016;21:48-52.

15. Ekstrom W, Samuelsson B, Ponzer S, Cederholm T, Thorngren KG, HedstromM. Sex effects on short-term complications after hip fracture: a prospective cohort study. Clin Interv Aging. 2015;10:1259-1266.

16. Man LP, Ho AW, Wong SH. Excess mortality for operated geriatric hip fracture in Hong Kong. Hong Kong Med J. 2016;22:6-10.

17. Moran CG, Wenn RT, Sikand M『et al. Early mortality after hip fracture: is delay before surgery important?.J Bone Joint Surg (Am). 2005;87(3):483489.

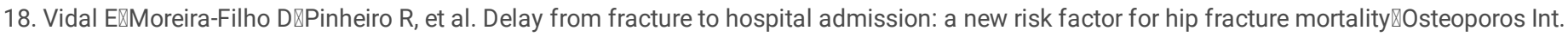
2012;23 (12):2847-2853.

19. Dokladalova P, Majernicek M, Vaculik J, Kubes R, Schwarz O, Dungl P.Results of surgically treated patients for hip fracture - complications,mortality. Acta Chir Orthop Traumatol Cech. 2017;84(6):424-430.

20. Frost SA, Nguyen ND, Center JR, et al. Excess mortality attributable to hip-fracture: A relative survival analysis. Bone. 2013;56(1):23-29.

21. Kesmezacar H, Ayhan E, Unlu MC, et al. Predictors of mortality in elderly patients with an intertrochanteric or a femoral neck fracture. Trauma. 2010;68(1):153-158.

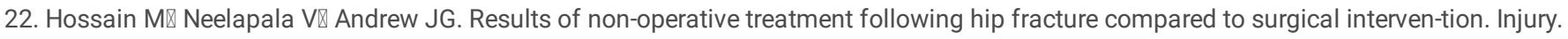
2009;40(4):418-421.

23. Vidan MT, Sanchez E, Gracia Y, et al. Causes and effects of surgical delay in patients with hip fracture: a cohort study. Ann Intern Med. 2011;155(4):226-233.

24. Novack V, Jotkowitz A, Etzion O, et al. Does delay in surgery after hip fracture lead to worse outcomes? A multicenter survey. Int J Qual Health Care. 2007;19(3):170-176.

25. Shiga T, Wajima Z, Ohe Y. Is operative delay associated with increased mortality of hip fracture patients? Systematic review, meta-analysis, and etaregression. Can J Anaesth. 2008;55(3):146-154.

26. Kim SD, Park SJ, Lee DH, et al. Risk factors of morbidity and mortality following hip fracture surgery. Korean J Anesthesiol. 2013;64(6):505-510. 
27. Choi HG, Lee YB, Rhyu SH, Kwon BC, Lee JK. Mortality and cause of death postoperatively in patients with a hip fracture: a national cohort longitudinal follow-up study. Bone Joint J. 2018;100B:436-442.

28. Fang XT, Ding LX, Chen YC,Yao Q, Zhang GA, Shen Y. Analysis of postoperative complications and causes of death in elderly patients with hip fracture. Chinese Journal of Gerontolog. 2010;30(17):2531-2532.

29. Harvey NC, McCloskey EV, Mitchell PJ, et al. Mind the (treatment) gap: aglobal perspective on current and future strategies for prevention of fragility fractures. Osteoporos Int. 2017;128:1507-1529.

30. Lyles KW, Colon-Emeric CS, Magaziner JS, et al. Zoledronic acid and clinical fractures and mortality after hip fracture. N Engl J Med. 2007;357:17991809. 